\title{
Beobachtung der Mondfinsterniss vom 17. Januar 1870.
}

The lunar eclipse of the $17^{\text {th }}$ instant was remarkably well seen here. The moon was overspread with very thin filmy cloud till about $11^{h} 43^{m}$, but the diminution of her brilliancy from that cause was very slight. She remained unclouded during the rest of the phenomenon. No decided defalcation of light was noticed on the castern $\operatorname{limb}$ till $10^{\mathrm{h}} 41^{\mathrm{m}}$, but at $10^{\mathrm{h}} \mathrm{5} 2^{\mathrm{m}}$, the effects of the penumbra were very marked. The following are the local mean times of the different phases as near as they could be observed it being a most difficult matter to fix the precise instants of the contacts owing to the ill-defined character of the shadow

First contact with the shadow... $17^{\mathrm{d}} 11^{\mathrm{h}} 1^{\mathrm{m}} 19^{\mathrm{s}}$

Beginuing of the total phase .... = 12029

End of the total phase........ = 133853

Last contact with the shadow... = 143858

\begin{tabular}{cc} 
Star. & Mag. \\
\cline { 1 - 2 }$a$ & $\boldsymbol{7}$ \\
$b$ & $8 \cdot 1$ \\
$c$ & 8 \\
$d$ & 8 \\
$e$ & 8 \\
$a$ & 7 \\
$f$ & 7
\end{tabular}

\begin{tabular}{|c|c|}
\hline Phase. & Mean Time. \\
\hline Disappearance & $11^{\mathrm{l}} 59^{\mathrm{m}} 24^{\mathrm{s}} 7$ \\
\hline$=$ & 1249,4 \\
\hline$=$ & 13219,3 \\
\hline$=$ & $\begin{array}{lll}13 & 5 & 0,2\end{array}$ \\
\hline Reappearance & $\begin{array}{lll}13 & 6 & 18,7\end{array}$ \\
\hline$=$ & $1325 \quad 4,2$ \\
\hline Disappearance & 133624,2 \\
\hline
\end{tabular}

The noted time of the reappearance of the star $a$, owing to a temporary removal of the eye from the telescope, was probably two or three seconds late. The monn's disc was of a copper hue throughout the total phase, and continued distinctly visible both to the naked eye and in the telescope. The southern limb was remarkably bright at the middle of the eclipse. The meridian transit of the first limb was pretty well observed, hut the second limb was too faint.
At $11^{\mathrm{h}} 29^{\mathrm{n}}$ the shadow assumed a light copper tint, except at its periphery where it was of a very dark green. The copper tint, as seen in the telescope, appeared to extend even to the filmy clond which lay along the moon's eastern limb. At $11^{\mathrm{h}} 43^{\mathrm{m}}$ when the moon shone unclouded, the details on the obscurel portion of the lunar surface began to be perceptible in the telescope. These became gradually more distinct, and it was soon observed that the dark body of the moon was surrounded by numerous telescopic stars, and that many occultations would occur during the total phase. Several of these phenomena were observed with tolerable accuracy: some of the stars, however, were too faint for accurate observation. The following occultations were recorded:

Risappearance sudien.
(approx.)
disappearances near upper limb: a little uncertain.
(approx.)
uncertain to a second owing to increasing brightnees of limb.

The copper and dark green tints were again observed after the total phase, that portion of the obscured surface next to the center of the shadow being copper tinted; and the outline of the shadow being very dark green. The telescopic observations during the eclipse were all made with my refractor of $3 \frac{1}{4}$ inches aperture and 48 inches focal length, furnished with a magnifying power of about 30 .

Windsor, N.S.Wales, 1870 Jan.26 th. J. Tebbutt junr.

\section{Schreiben des Herrn Commodore B. F. Sands an den Herausgeber.}

I have the pleasure of transmitting to you some observations of the stars of comparison observed with the planet Felicitas, 200 . The observations were made by Professor Safford of the Dearhorn Observatory at Chicago, with his new Repsold Meridian Circle. The following is an extract from Professor Safford's letter:

,The following are places of some stars $I$ have observed with our Meridian Circle; anong them are some used at the U. S. Naval Observatory to conpare with Felicitas, $10 \mathrm{y}$.

I. S. Naval Observatory, Washington, 1870 March $19^{\text {th. }}$

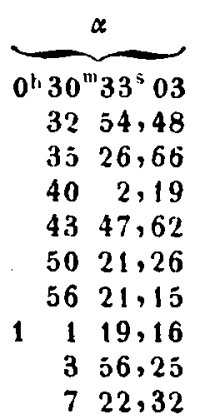

\begin{tabular}{|c|c|c|}
\hline & $\delta$ & To of Obs. \\
\hline$+10^{\circ}$ & $43^{\prime} 15^{\prime \prime} 6$ & 2 \\
\hline 10 & $49 \quad 4,4$ & 2 \\
\hline 10 & 621,0 & 1 \\
\hline 9 & 5149,3 & 3 \\
\hline 9 & 4211,7 & 2 \\
\hline 9 & 4342,3 & 4.3 \\
\hline 9 & 3755,6 & 2 \\
\hline 14 & 2550,2 & 1 \\
\hline 14 & 4313,5 & 1 \\
\hline+15 & 1626,0 & $1 *)$ \\
\hline
\end{tabular}

*) Star faint, 2 wires only obtained for $A R$. These however agrec well. Probable error of 10 bservation \pm 0 062, $\pm 0 " 61$." 